The University of San Francisco

USF Scholarship: a digital repository @ Gleeson Library | Geschke Center

Nursing and Health Professions Faculty Research and Publications

School of Nursing and Health Professions

2016

\title{
Reflections on Leadership in Nursing Education: A Minority Perspective
}

Angela Banks

University of San Francisco, adbanks@usfca.edu

Chenit Ong-Flaherty

University of San Francisco, congflaherty@usfca.edu

Claire Sharifi

University of San Francisco, cosharifi@usfca.edu

Follow this and additional works at: http://repository.usfca.edu/nursing_fac

Part of the Educational Leadership Commons, and the Nursing Commons

\section{Recommended Citation}

Banks, A.D., Ong-Flaherty, C., Sharifi, C. (2016). Reflections on Leadership in Nursing Education: A Minority Perspective. Creative Nursing, 22(2), 88-91. http://dx.doi.org/10.1891/1078-4535.22.2.88

This Article is brought to you for free and open access by the School of Nursing and Health Professions at USF Scholarship: a digital repository @ Gleeson Library | Geschke Center. It has been accepted for inclusion in Nursing and Health Professions Faculty Research and Publications by an authorized administrator of USF Scholarship: a digital repository @ Gleeson Library | Geschke Center. For more information, please contact repository@usfca.edu. 
Reflections on Leadership in Nursing Education: A Minority Perspective

Angela Denise Banks, RN, PhD; Chenit-Ong Flaherty, RN, CNL, APH-BC, DNP; and Claire Sharifi, MLIS

Angela Denise Banks, RN, PhD, is an Associate Professor of Nursing and Chair of the

Baccalaureate Nursing Department at the University of San Francisco, in San Francisco, California.

Chenit-Ong Flaherty, RN, CNL, APH-BC, DNP, is an Assistant Professor in the Graduate Nursing Department at the University of San Francisco in San Francisco, California.

Claire Sharifi, MLIS, is an Assistant Librarian at the University of San Francisco in San Francisco, California.

Correspondence about this article should be addressed to Angela Denise Banks, RN, PhD, at adbanks@usfca.edu

Shortened article title: Leadership in Nursing Education

\section{Abstract}

Academic leadership is at once engaging and stimulating, demanding and overwhelming. This paper discusses the experiences and perspectives of minority faculty members working at a Jesuit institution. In this paper, the authors utilize Ignatian pedagogical values as the foundation 
to guide their responses to the challenges they experience in leadership roles, and to turn these challenges into opportunities for growth.

Keywords: Leadership, minority, Ignatian values, Jesuit Institution, nursing education

Database searches for scholarly articles on the leadership experience of minority faculty in nursing yield a wealth of publications, from narratives to studies. In the last ten years, there has been growth in open and candid publications that discuss how minority nurse educators and leaders struggle with exclusion and inequity. Having more literature is encouraging, but the reality of minority representation in nursing education, particularly nursing education leadership, has not changed much. While diversity among faculty is key to recruiting and retaining a diverse student body, nursing faculty are predominantly middle-aged white women (Bleich, MacWilliams, \& Schmidt, 2015; Mills-Wisneski, 2005), and this holds true in schools located in even the most diverse areas of the United States, and in schools where the nursing student population reflects the greater geographical region’s diversity. This cultural incongruence between faculty and the broader population affects not only students and their learning, but also the few minority faculty members who strive to become successful in academia.

The authors are all employed by a Jesuit University. Ignatian pedagogy, a pedagogical approach inspired by the teachings of St. Ignatius of Loyola, serves as the foundation of Jesuit education. The Ignatian emphasis on Experience, Reflection, and Action is taught to our students, and, in an effort to 'practice what we preach,' the authors are using Ignatian pedagogy as the foundation for this paper. This paper is a reflective piece on the challenges of being a minority faculty member, 
on navigating the dominant culture within an institution, and on encountering both conscious and unconscious biases that can make the simplest daily activities a challenge.

\section{BACKGROUND}

Historically, white females have been the dominant population in the nursing profession. While the profession has diversified in recent years, whites still make up more than $75 \%$ of the RN workforce (U.S. Department of Health and Human Services, 2013). The numbers of Black/African American RNs and Hispanic/Latino RNs are slowly increasing, yet when these two demographics are compared to the current U.S. working age population, both are still significantly underrepresented (U.S. Department of Health and Human Services, 2013). The racial, ethnic, and linguistic demographics of health care have significant implications for the health of the populace. Evidence shows that race, ethnicity, and language concordance are associated with better patient and practitioner relationships, better communication, and the increased likelihood of patients receiving and accepting appropriate health care (U.S. Department of Health and Human Services, 2006). Minority health professionals also serve a greater proportion of the minority and underserved patient population.

The Institute of Medicine’s 2003 report, Unequal Treatment: Confronting Racial and Ethnic Disparities in Health Care, called for an increase in the number of underrepresented minorities in the health care workforce, in part as a way of providing culturally competent care at a systematic, organizational level (Jackson \& Gracia, 2014). In order to increase the diversity of the nursing profession, nursing schools must attract, retain, and support both diverse students and diverse faculty (Bleich et al., 2015; Zajac, 2011). Bleich et al explain the extra work nursing 
school leaders must undertake if diversity among_nursing faculty is to improve. These steps include examining the meaning of tenureship and the practice of hiring based on tokenism. Alienation, a sense of not belonging, is experienced by many minorities in nursing education (Hassouneh \& Akeroyd, 2013; Robinson 2014), but through those Ignatian Pedagogical values, reflecting on difficult experiences, learning from these reflections, and moving forward and onward, the authors who are faculty members are able to become full-fledged members of the larger nursing faculty. It is thus demonstrated that Ignatian pedagogy has a direct role in guiding other minority faculty members to adapt to the challenges of academia as it did for these authors teaching at a Jesuit University.

\section{IGNATION PEDAGOGY}

Saint Ignatius of Loyola founded the Society of Jesus, commonly known as the Jesuits, in 1540 (The Jesuit Curia, n.d.). The Jesuits are recognized for their commitment and dedication to education. Through the centuries, the Society has opened schools and institutions of higher education across the world based on the ethics of social justice and common good, in the belief that every individual is connected to the world and that all human beings have the potential to grow to become better individuals (Jesuit Institute, 2015). Magis—seeking the betterment of self and others, and of the environment in which we live-is central to Ignatian teaching. The learning process is Socratic in nature, dialectical, cyclical, and never-ending, of a shared practice between a teacher and a student. In this relationship, an Experience is provided and "lived" together, Reflection is guided and fulfilled, and Action is taken to improve on the lived experience (Jesuit Institute, 2015). 
The authors of this article appreciate that Ignatian teaching essentially starts with the examination of self. One must start a dialectical conversation with God or a higher authority, questioning one’s existence, ego, decisions, and actions, many times coming to humbling conclusions. The purpose of this paper is not one of taking a position on God or on Jesuit values. We believe that Jesuit values of social good and reflective practice are universal across spiritual beliefs. Thus we find ourselves infusing what we are to share with our students into our many roles as faculty members: teacher, student, leader, community activist, colleague, advocate, and servant.

\section{EXPERIENCE}

Minority faculty members constitute approximately 8\% of the School of Nursing at this urban university. Faculty members of color often feel invisible, and wonder how to survive the isolating, competitive environment of academia. Frequently, the advice given is that to attain tenure ${ }_{2}$ one must sell oneself. One must have confidence in one's abilities, and this characteristic must be loudly announced and widely known — a direct contradiction to the values shared by many minority cultures, collectivist in nature, in which the self comes second to the good of the group or community (Triandis, 2004). In leadership initiatives, we have experienced a lack of buy-in from our colleagues. Convincing fellow faculty members to envision a new and innovative way to accomplish things has sometimes been difficult; $\underline{\text { at }}$ other times, we have been supported and encouraged.

\section{REFLECTION}


Reflecting on the issue of getting buy-in from our colleagues, we realized early in this journey that honesty, transparency, and respect for colleagues’ opinions are necessary to initiate change. We understood that our ideas and recommendations are not the only suggestions to consider when addressing departmental issues. We realized that it is not possible to meet every individual demand. We appreciated that effective cultural exchange and developing cultural awareness takes time and much effort from all sides. As long as our decisions are made by consensus for the good of the group or community, it is the very best we can do.

\section{ACTION}

Acting on our reflections, we understood the importance of allowing all sides to discuss concerns and to offer constructive criticism and alternative ideas when addressing departmental issues. It is pivotal to provide a platform for sufficient discussion. Additionally, understanding that any change is challenging for some people was a crucial step. We chose to be flexible in our communication and interaction with all faculty members by listening to everyone and seeking consensus. From listening, respecting, and acknowledging the contributions of others, we have gained peace, tranquility ${ }_{2}$ and insight. It is with this awareness, and true to the Ignatian values of “experience, reflection and action,” that we are able to live our lives as minority faculty members, day by day, always moving onward and forward.

\section{IMPLICATIONS AND CONCLUSION}

Minority faculty members face unique challenges in succeeding in academia. More members are now more willing to share their experiences. These authors share how they use the Ignatian approach of experience, reflection, and action to help them manage the difficulties that come 
from having values and perspectives that differ from the dominant culture. It is in quiet reflection on our experiences, learning from being outsiders, that we make decisions to take positive action. We are fortunate to have each other to share and reflect with, and to support and guide each other through our challenging times. Change starts with each and every_one of us. As Bleich et al (2015) clearly stipulate, inclusivity is imperative for the future of nursing. As we maneuver through the trials of academia, we encourage other minority faculty members to contact us, as we would be glad to communicate with them and move forward and onward together.

\section{References}

Bleich, M.R., MacWilliams, B.R., \& Schmidt, B.J. (2015). Advancing diversity through inclusive excellence in nursing education. Journal of Professional Nursing, March/April 31(2), 89-94.

Hassouneh, D., Akeroyd, J., Lutz, K. F., \& Beckett, A. K. (2012). Exclusion and control: patterns aimed at limiting the influence of faculty of color. Journal Of Nursing Education, 51(6), 314-325 12p. doi:10.3928/01484834-20120323-04

Jackson, C. S., \& Gracia, J. N. (2014). Addressing Health and Health-Care Disparities: The Role of a Diverse Workforce and the Social Determinants of Health. Public Health Reports, 129(Suppl 2), 57-61.

Jesuit Institute. (2015). Ignatian Pedagogy: a practical approach. http://jesuitinstitute.org/Resources/Ignatian Pedagogy (JI Edition 2013).pdf

The Jesuit Curia, n.d. The Jesuit curia in Rome. http://www.sjweb.info/

Triandis, H. C. (2004). The many dimensions of culture. Academy of Management Executive, (18) 1 . 
Mills-Wisneski, S. (2005). Minority students' perceptions concerning the presence of minority faculty: inquiry and discussion. Journal Of Multicultural Nursing \& Health (JMCNH),11(2), 49-55 7p.

Robinson, O. V. (2014). Characteristics of racism and the health consequences experienced by black nursing faculty. ABNF Journal, 25(4), 110-115 6p.

U.S. Department of Health and Human Services. (2006). The Rationale for diversity in the health professions: A review of the evidence. Retrieved from http://bhpr.hrsa.gov/healthworkforce/reports/diversityreviewevidence.pdf

U.S. Department of Health and Human Services. (2013). The U.S. nursing workforce: Trends in supply and education. Retrieved from http://bhpr.hrsa.gov/healthworkforce/supplydemand/nursing/nursingworkforce/nursingwo rkforcefullreport.pdf

Zajac, L. (2011). Double-loop approach: Recruitment and retention of minority nursing faculty. ABNF Journal, 22(3), 73. 